\title{
Inorganic hydrophobic coatings: Surfaces mimicking the nature
}

\author{
Julián J. Reinosa , Juan. J. Romero, Miguel A. de la Rubia, Adolfo del Campo, \\ José F. Fernández
}

\begin{abstract}
Added value products are being developed in ceramic industry. Different optical effects as bright metallic shine or new functionalities as hydrophobicity or bactericide characteristics are the new properties searched on the tiles. In this study, we prepare glassy coatings for tiles based on copper pigment by a conventional industrial process. The obtained coatings present different aesthetical aspects, including bright metallic aspect which confers a high decorative value to the tile. Furthermore, these metallic coatings present hydrophobic properties with contact angles with water as high as $115^{\circ}$ and also bactericide characteristics. Superficial microstructure and nanoparticles were found in the bactericide-hydrophobic samples, resembling the surface of hydrophobic leaf surfaces. This structure was formed by the crystallization of $\mathrm{CuO}$ nanoparticles as Tenorite due to the copper saturation of the glassy matrix at the surface of the coatings.
\end{abstract}

Keywords: B. Microstructure-final; B. Surfaces; D. Glass; E. Functional applications

\section{Introduction}

Surfaces showing an apparent contact angle larger than $90^{\circ}$ with liquids, and most specifically with water, are considered hydrophobic surfaces, while those presenting contact angles higher than $150^{\circ}$ are super-hydrophobic [1]. Super-hydrophobic surfaces have attracted significant attention for their potential use in many different applications [2]. In this field, a broadly followed tendency is to mimic the structural design of natural super-hydrophobic leaves [3], particularly those of the Lotus flower (Nelumbo Nucifera). These leaves present contact angle with water droplets over $150^{\circ}$, producing nearly spherical droplets that roll over the leaves instead of sliding. This fact impedes the wetting of the leaves and also removes superficial contaminants that are taken away by the rolling water drops. The superhydrophobic properties of the lotus leaves are based on the hierarchical combination of microand nano-structures on their surface, together with the presence of hydrophobic molecules [4]. Different studies reveal that the surface texture pattern is a key factor of the hydrophobic properties of these leaves $[5,6]$, and hence, hierarchically structured surfaces presenting hydrophobic properties are expected to present lotus effect [7]. In particular, in the case of nanostructured surfaces, where composite Cassie-Baxter interfaces appear between the surfaces and water drops [8], it is demonstrated that increasing the nanoroughness (or fraction of intergranular empty spaces on the surface) leads to higher contact angle, i.e., the hydrophobic character of the surface, makes this effect even more evident when a microstructuration of the surface is also present.

In the Lotus leaves, surface structuring arises at different hierarchical levels. At the micro-scale, the epidermal cells create a sculpturing of the surfaces; the surface of each cell presents a further structuration at the nanoscale produced by the presence of nanosized hairs or tubules [9]. In other words, two main surface morphologies are present, one at micrometer size, due to the different cells, and another one at nanometer size, corresponding to the structures present at the surface of each cell.

A number of methods have been reported in the literature to fabricate structures similar to the ones found on 
hydrophobic plants, including plasma [10], laser and chemical etching $[11,12]$, lithographic patterning, electrochemical deposition, sol-gel, coating-by-coating assembly and chemical or vapor deposition [13]. However, these methods present certain limitations for industrial applications and have not been transferred to commercial products because most of them are only applicable on small substrates and require either time consuming processing steps or expensive machinery [14]. Moreover, hydrophobic and super-hydrophobic coatings are usually mechanically instable and do not even resist wiping with a cloth, highly limiting their potential uses. Therefore, a simple, inexpensive and convenient strategy to form patterned structures is highly needed.

In the same way, bactericide surfaces are pursued in combination with auto-clean surfaces. The activity in the field of inorganic bactericides is related to materials supporting silver or copper metal nanoparticles [15,16], nanorough surfaces [17] or photocatalytic nanoparticles [18]. However, the industrial implantation of photocatalytic function is not an easy task. As an example, the coatings must be irradiated with UV light to achieve the desired characteristics, representing a serious limitation.

The ceramic tiles industry is one of the fields where applications of hydrophobic and bactericide surfaces are straightforward. The potential of producing self-cleaning surfaces would mean a paramount advance on this market, both for the public and for the manufacturing companies $[19,20]$. The main problems that must be solved in order to incorporate new functionalities to ceramic tiles are the high temperatures used in their fabrication (about $1000{ }^{\circ} \mathrm{C}$ or higher) and the highly reactive components employed. Moreover, high production rates and low production costs are also common requirements of this market. And finally, these products must present some technical characteristics and more specifically high wear strength, being not affected by common use.

In order to satisfy the necessities of the ceramic sector, nanostructured hydrophobic ceramic glazes were previously developed by adding metallic nanoparticles supported on sepiolite fibers [21]. This method was compatible with the standard fabrication process of tiles but the metallic nanoparticles supported on sepiolite were not commercially available because of the product cost. The new challenge is to develop new nanostructured functional glazes using available materials in the market.

In this work we present new developments on bactericidehydrophobic surfaces for industrial ceramic tiles by using $\mathrm{Fe}_{2} \mathrm{O}_{3}$ and $\mathrm{Cu}$ microparticles. The sintering procedure was the same fast-firing process commonly employed in the industry for the preparation of ceramic tiles. The bactericide-hydrophobic coating so obtained possesses a hierarchical structure similar to that of the hydrophobic leaf surfaces and it is resistant enough to be used in standard applications.

\section{Experimental procedure}

Hydrophobic glazes were prepared following a standard procedure in the ceramic tile industry [22]. For the preparation of the glaze, an homogeneous suspension in water of commercial frit, Kaolin, $\mathrm{Fe}_{2} \mathrm{O}_{3}$ and metallic copper was prepared. The frit corresponds to an industrial standard used in stoneware industry and was supplied by Kerafrit S.A. The composition of this frit is shown in Table 1. Metallic copper particles, with an average particle size of $3 \mu \mathrm{m}$ and $\mathrm{Fe}_{2} \mathrm{O}_{3}$ particles with size $<5 \mu \mathrm{m}$ were purchased from Aldrich. The solid content was $40 \% \mathrm{wt}$ and the relative mass proportion of each component on the solid was: $78 \%$ wt frit, $10 \%$ wt $\mathrm{Cu}, 5 \%$ wt $\mathrm{Fe}_{2} \mathrm{O}_{3}$ and $7 \%$ wt kaolin.

The suspension was homogenized by ball milling for a period of $20 \mathrm{~min}$ using $0.2 \% \mathrm{wt}$ of sodium trypolyphosphate as deflocculant and $0.2 \%$ wt of carboxymethyl cellulose to improve the adhesion of the glaze to the green tile. The suspension was sprayed on the surface of a stoneware green tile substrate producing coatings with thicknesses ranging from $50 \mu \mathrm{m}$ to $250 \mu \mathrm{m}$. Then, the tiles with the glaze coatings were dried at $90{ }^{\circ} \mathrm{C}$ and fast-fired in an air atmosphere using a Pirometrol furnace. The heating rate was ca. $30^{\circ} \mathrm{C} / \mathrm{min}$ and the maximum temperature was $1200^{\circ} \mathrm{C}$ (held for $5 \mathrm{~min}$ ). This sintering cycle corresponds to a standard industrial fast-firing process of stoneware ceramic tiles. The total firing cycle was $55 \mathrm{~min}$.

The glaze surfaces were characterized by X-ray diffraction analysis, performed with $\mathrm{Cu} K \alpha$ radiation using a Siemens D500 Diffractometer in grazing angle $\left(0.5^{\circ}\right)$ the step time being $2 \mathrm{~s}$ with an increase of $0.02^{\circ}$. The crystallite size was studied from XRD using the Debye-Scherrer equation. The roughness of the surface was measured with a Surtronic 3+ roughmeter from Taylor Hobson Precision (England) taking account the Ra value (average of profile variation on the vertical axis). The microstructure was studied by a field emission scanning electron microscope (FE-SEM, Hitachi S-4700) and the nanostructure was studied by atomic force microscope (AFM) in noncontact mode with a WITec 300 microscope and by transmission electronic microscope (JEOL JEM-2100F) at $300 \mathrm{kV}$. The samples were slimmed for TEM study using a Dimple Grinder and an ion miller from Gatan. Water contact angle was measured with the drop shape analysis system Easy Drop Standard from Krüss using deionized water drops of $4.0 \pm 0.1 \mu \mathrm{L}$.

The bactericide characteristics of the coatings were measured according to the standard JIS $Z$ 2801. Control and test surfaces are inoculated with $10^{5}$ colony-forming units (CFU) of microorganisms and they are allowed to incubate undisturbed in a humid environment for $24 \mathrm{~h}$. After incubation, microbial concentrations are determined. Reduction of microorganisms relative to initial concentrations and the control surface is calculated according to the parameter $R$, bactericide effect is consider when $R>2$.

$R=\log \frac{C F U_{\text {on control sample }}}{C F U_{\text {on test sample }}}$ 


\section{Results and discussion}

The tiles prepared in this study were fabricated following an industrial procedure and consisted of a glaze coating containing copper and iron on a conventional stoneware substrate. Glaze coatings of different thicknesses were sintered to produce different colors and effects (see Fig. 1). A greenish-brown color glaze was obtained for $\sim 50 \mu \mathrm{m}$ (hereafter S50) in thickness coating; brown glaze with iridescent effects $\sim 100 \mu \mathrm{m}$ (hereafter S100); bright metallic effect with a dark background for $\sim 150 \mu \mathrm{m}$ (S150); and matt metallic effect was characteristic of $\sim 200 \mu \mathrm{m}$ (S200). Samples with glaze thickness $\sim 250 \mu \mathrm{m}$ (S250) present a microrough surface with an aspect similar to that of leather type and dark gray color. $\mathrm{Fe}_{2} \mathrm{O}_{3}$ was added to the composition in order to obtain the metallic effect. It is described that iron in glasses provokes a darkness of the glassy matrix [23]. The presence of a dark background is a key point for obtaining the bright metallic effect.

The coatings present a well compacted flat surface, free of pores or unmelted inclusion. The micro-roughness of these coatings has been measured with a roughmeter, giving a value of $\mathrm{Ra} \sim 0.05 \mu \mathrm{m}$ for green color glazes ( $\mathrm{S} 100$ ), similar to that of commercial glazes. The roughness of surfaces increases with the coating thickness, reaching values of $\mathrm{Ra} \sim 0.11 \mu \mathrm{m}$ on the metallic surface coatings (both bright and matt, $\mathrm{S} 150$ and $\mathrm{S} 200$ ) and up to $\mathrm{Ra} \sim 2.17 \mu \mathrm{m}$ for $\mathrm{S} 250$.
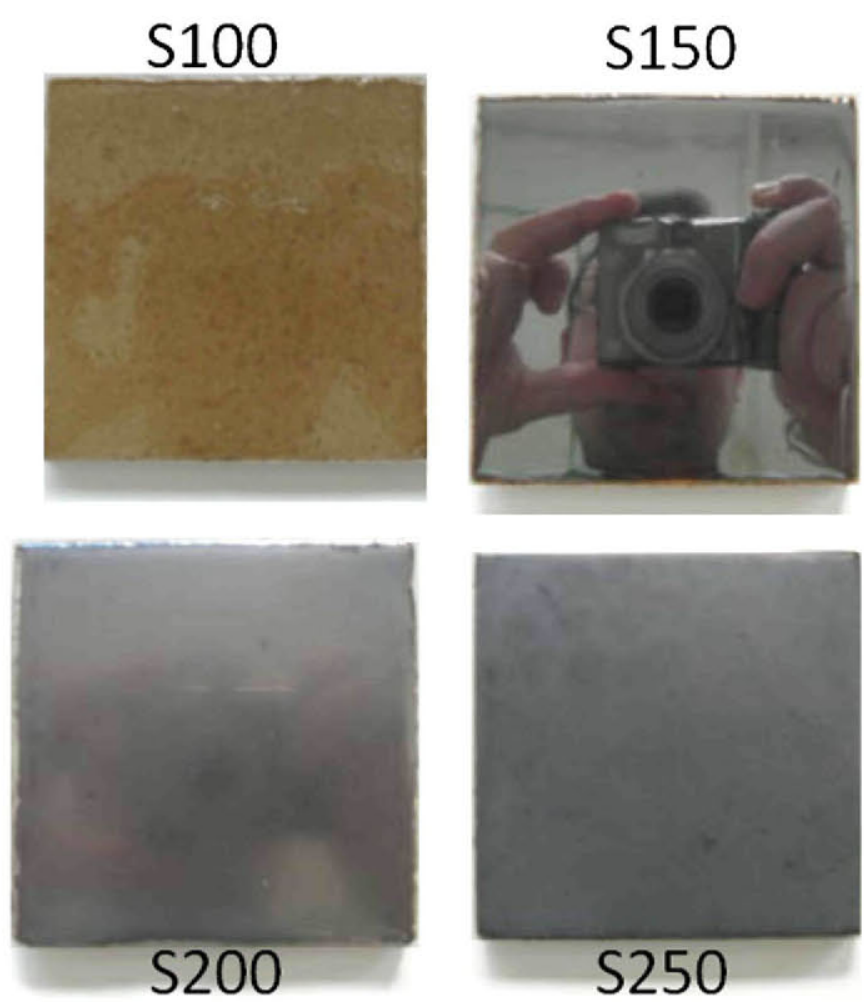

Fig. 1. Photo images of the samples carried out by applying different thicknesses of glaze coating.
Grazing angle X-ray diffractograms of the samples with different thickness were taken to study the nature of the crystalline phases appearing on the coating surface (Fig. 2). At low angles $\left(2 \theta=20-40^{\circ}\right)$ a broad band corresponding to the amorphous glassy phase is observed. This band is the only feature observed on coatings with thickness below $100 \mu \mathrm{m}$ (S50), whereas for thicker samples a crystalline phase is observed. This phase corresponds to $\mathrm{CuO}$, crystallized on the Tenorite phase (JCPDS card number 48-1548), and its presence seems to keep constant from $\mathrm{S} 100$ to $\mathrm{S} 200$ and increases with the thickness of the coating from S200. After the previous results [21], this crystalline phase should appear only at the surface of the sample and is responsible for the increase in surface roughness. The crystallite size of the Tenorite phase was estimated from the XRD measurements and ranged from ca. $15 \mathrm{~nm}$ for $\mathrm{S} 100$ to nearly $90 \mathrm{~nm}$ on the thicker glaze coatings (see inset in Fig. 2). A similar situation has been previously described for other metallic cations on ancient glazes [24].

The different optical effects and the formation of the Tenorite phase are related to a limited solubility of the copper in the glassy phase of the coating. Initial metallic copper particles dissolve in the glassy matrix, the copper cations saturate the glassy phase and segregate as copper oxide on the surface. So, applying the same glaze with a determined copper concentration, we are able to obtain surfaces with different Tenorite crystallite size, thanks to the copper migration towards the surface. The amount of Tenorite at the surface of the coating produces the different aesthetical aspects observed as a function of the coating thickness. The greenish-brown color of the thinnest coating is the characteristic of copper and iron, respectively, dissolved in the glassy phase (S50) [25], and

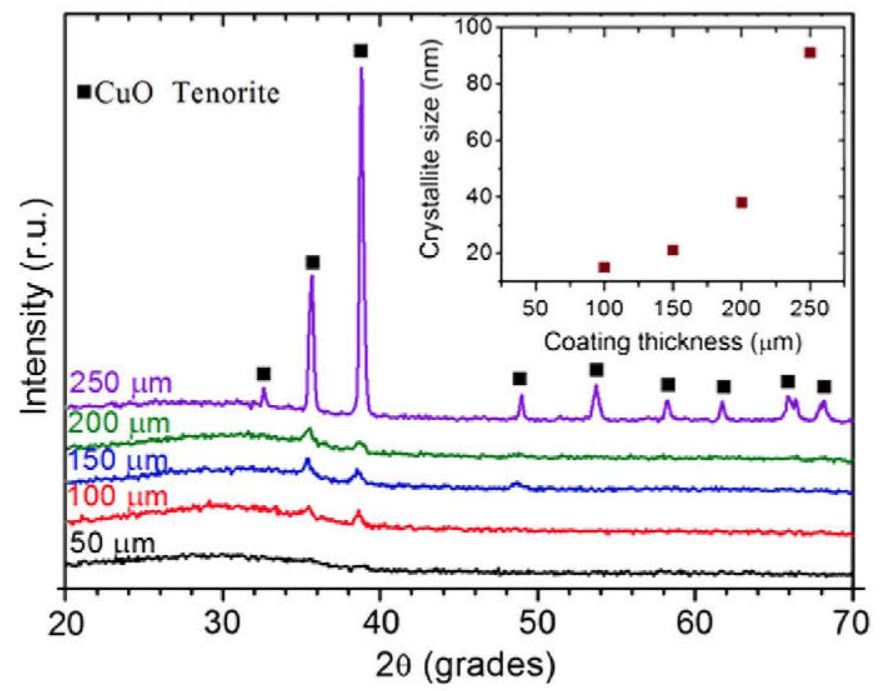

Fig. 2. XRD patterns of the samples depending on the thickness of glaze coating. All samples show a wide band with low intensity corresponding to the glassy matrix and $\mathrm{CuO}$ crystallized as Tenorite. Inset represents the crystallite size depending on the glaze coating thickness calculated using Debye-Scherrer equation. 
a very limited amount of copper is segregated from the phase due to the small thickness of the glaze coating. When the coating thickness increases, the copper cations migrates towards the surface due to its high mobility on melted glassy matrix [26] giving rise to a copper saturated surface. The copper oxidizes to $\mathrm{Cu}_{2} \mathrm{O}$ and $\mathrm{CuO}$ in the presence of oxygen at high temperature, and crystallizes as Tenorite. Due to the fast firing process employed, the $\mathrm{CuO}$ crystals present a nanometer size.

The contact angle of a water drop has been measured for the different glaze coatings and the results are shown in Fig. 3. As can be seen, the glazes with lower thickness (S50, green color samples) present a contact angle of $\approx 60^{\circ}$, very

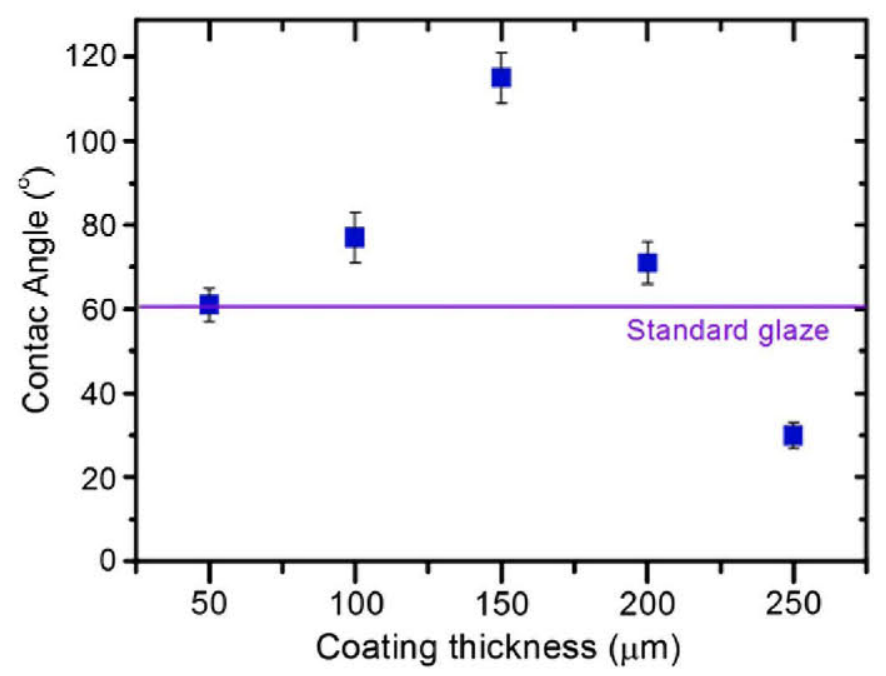

Fig. 3. The contact angle of the samples depending on the glaze coating thickness.
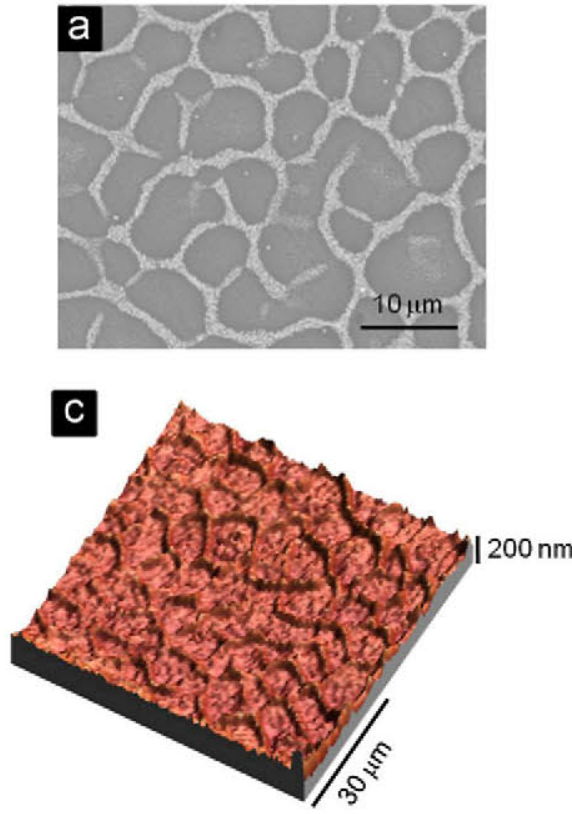

similar to that of a standard glaze. As the glaze thickness increases the contact angle increases up to a maximum of $115^{\circ}$ obtained for sample S150, which presents a metallic aspect. This value is close to the one usually presented by Teflon [27], a widely used anti-adherent material, and is higher than previous results obtained from the experimental procedure with metal nanoparticles supported in sepiolite [21]. Further increase of the glaze thickness produces a decrease of the contact angle, showing values lower than $90^{\circ}$ for the thickest prepared samples. Then, it is evident that coatings having thickness nearly $150 \mu \mathrm{m}$ present hydrophobic characteristics, sample S150.

SEM micrographs of samples $\mathrm{S} 150$ and $\mathrm{S} 200$ are shown in Fig. 4. The thinnest sample, S50, shows a flat surface (not shown here for the sake of brevity), very similar to the one usually found on commercial tiles. S100 has an intuitive structure that is clearly seen on S150, corresponding to Fig. 4a. The surfaces of S150 (Fig. 4a) and S200 (Fig. 4b) present a pseudo-cellular structure (hereafter, cellular regions), that resemble the one found on the surface of hydrophobic leaves [28]. Sample S250 presents a rough surface (not shown here for the sake of brevity) due to the presence of high amount of Tenorite crystallizations. Then, the hydrophobic character of these tiles should be associated to some extent of this surface structure. Nonetheless, only the coatings with thickness about $150 \mu \mathrm{m}$ present contact angles clearly over $90^{\circ}$.

In order to further study the structural differences between these sample surfaces, AFM characterization was performed. AFM images of the topography of samples S150 and S200 are shown in Fig. 4c and d, respectively. In these micrographs, the cellular structure in sample $\mathrm{S} 150$ is clearly observed whereas it is not so well defined in sample
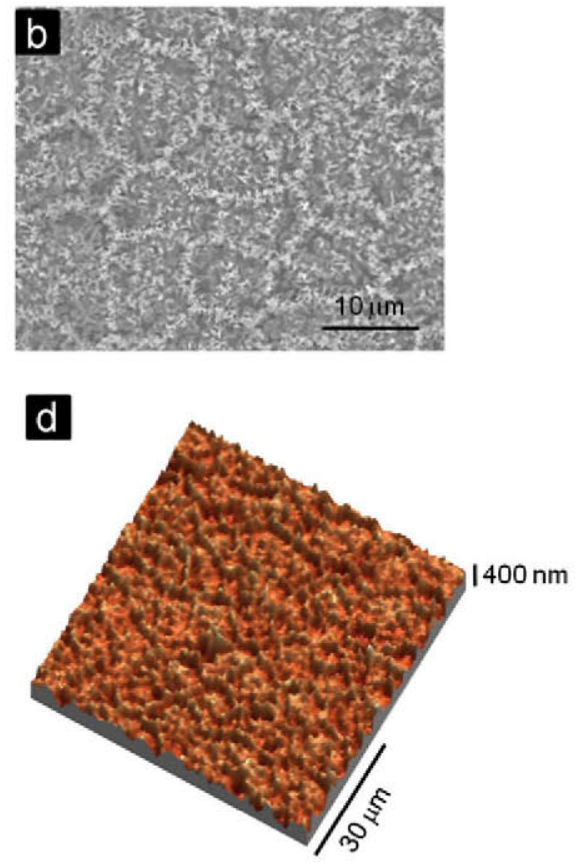

Fig. 4. (a) SEM micrograph of the surface of the S150 glaze, (b) SEM micrograph of the surface of S200 glaze, (c) 3D representation of the S150 studied by AFM, and (d) 3D representation of S200 studied by AFM. 

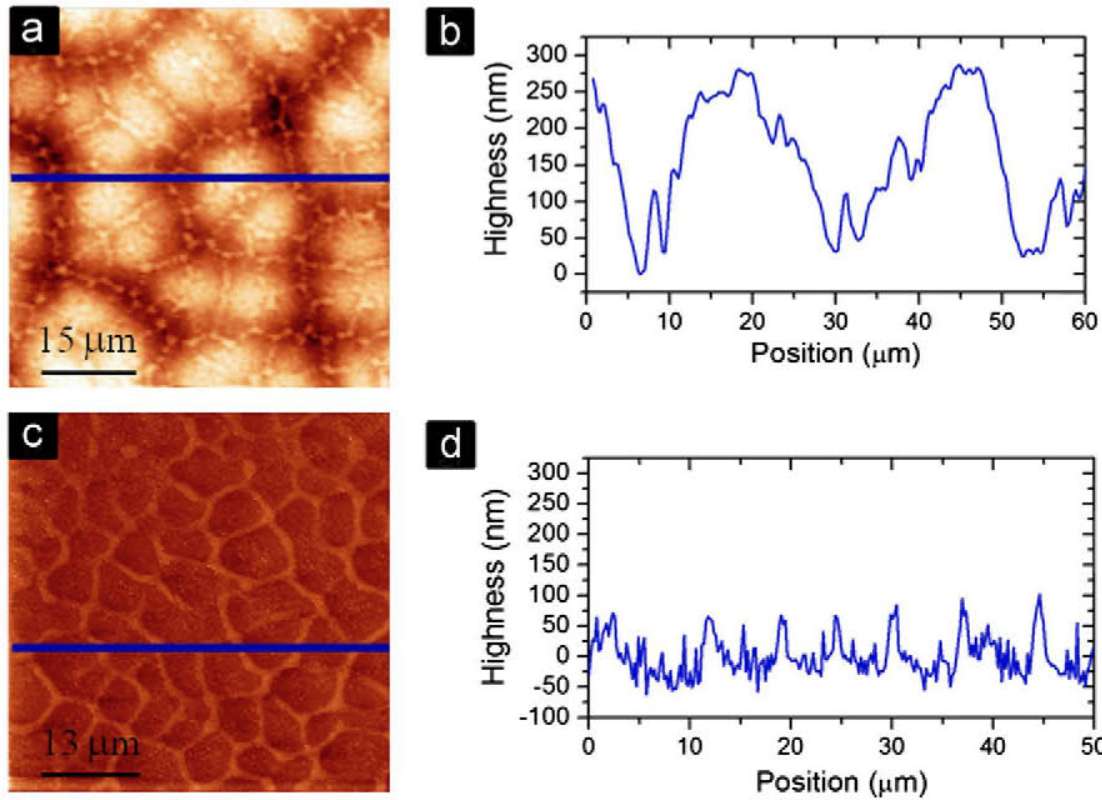

\section{d}
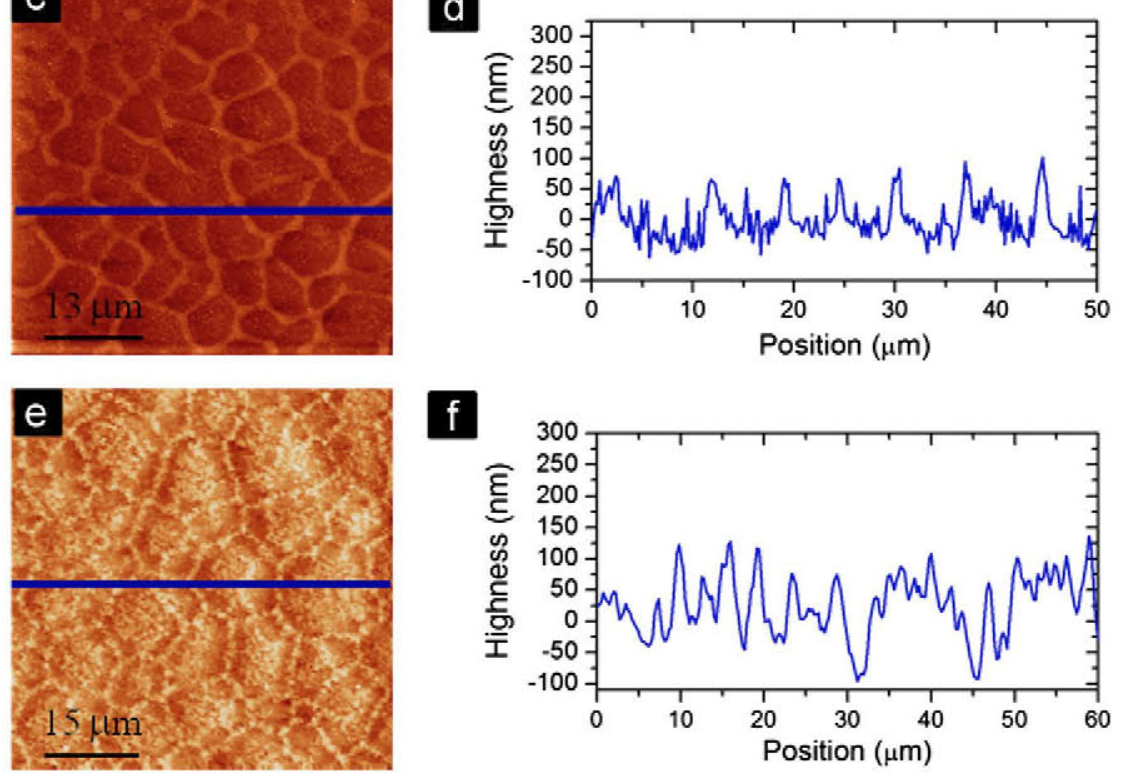

Fig. 5. (a) Microstructure of S100 (greenish-brown coating) observed by atomic force microscopy (AFM), (b) roughness profile from the AFM image, (c) microstructure of $\mathrm{S} 150$ (bright metallic effect) observed by atomic force microscopy (AFM), (d) roughness profile from the AFM image, (e) microstructure of S200 (matt metallic coating) observed by atomic force microscopy (AFM), and (f) roughness profile from the AFM image. (For interpretation of the references to color in this figure legend, the reader is referred to the web version of this article.)

S200 even through the crystallization of Tenorite is intuited in the interior of the cells.

AFM images and topographic profile of samples S100, S150 and S200 are compared in Fig. 5 in order to differentiate the structure related to the contact angle of the coatings. Sample S100 (Fig. 5a and b) is composed of convex globular structures, $\sim 20 \mu \mathrm{m}$ broad, separated by depressions $\sim 5-7 \mu \mathrm{m}$ broad. The maximum difference between the depressions and the highest point of the globular structure is $\sim 0.25 \mu \mathrm{m}$. Sample S200 (in Fig. 5c and 5d) does not present the globular structure, and in this case walls delimiting cells are perfectly observed. These walls are lower than in sample S100. Sample S200 (Fig. 5e and $\mathrm{f}$ presents more roughness and the high of the walls increases. In S250 the structure cannot be identified (not shown here for the sake of brevity).

A higher magnification study of $\mathrm{S} 150$ by transmission electron microscopy reveals the presence of some smaller features decorating the whole surface of the cellular structure. The presence of the nanoparticles is clearly observed in Fig. 6a. Moreover, some amorphous phase appears covering the crystalline nanoparticles, which could explain the apparent increase in size of the features observed by AFM in respect to the Tenorite crystallite size obtained from XRD. The atomic planes of the nanoparticles present on the surface can be clearly seen in Fig. 6b. A distance between planes of $2.54 \AA$ has been measured, in good agreement with distances between planes in direction $\left(\begin{array}{lll}1 & 1-1\end{array}\right)$ for the Tenorite phase.

The hydrophobic characteristics observed on samples should then be related in some way to the presence of this surface nanostructure. Moreover, the high contact angle observed on sample S150 is related to a hierarchical combination of both the globular structure and the superimposed nanostructure. The surface of this sample clearly resembles the hierarchical structure observed on the leafs of Tropaeolum Majus and Colocasia Esculenta, well known hydrophobic plants [29].

The formation of the cellular structure and the Tenorite decoration can be explained by the convective currents occurring on the melted glass, giving rise to the well known Rayleigh-Bernard (R-B) cells [30]. The observed structure is similar to the one found when convection currents take place in a fluid. During the cooling step in the sintering 

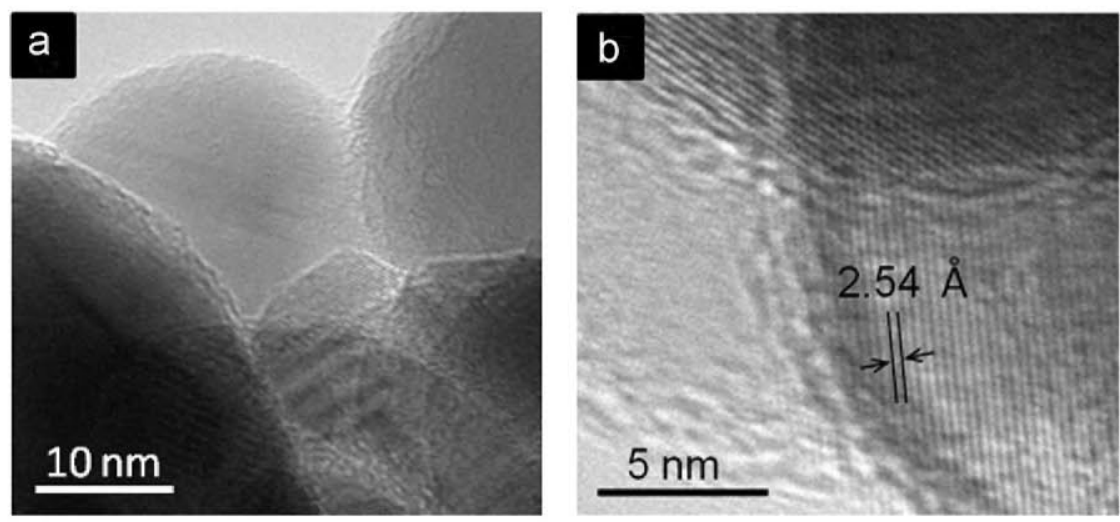

Fig. 6. (a) Nanostructure of S150 (bright metallic aspect) observed by transmission electronic microscopy, and (b) detail of the interplanar distance of nanocrystallizations in Fig. 6a.

Table 1

Chemical composition by XRF of the frit used to prepare the glazes.

\begin{tabular}{llllllllll}
\hline & $\mathrm{SiO}_{2}$ & $\mathrm{Fe}_{2} \mathrm{O}_{3}$ & $\mathrm{MgO}$ & $\mathrm{Na}_{2} \mathrm{O}$ & $\mathrm{Al}_{2} \mathrm{O}_{3}$ & $\mathrm{~K}_{2} \mathrm{O}$ & $\mathrm{CaO}$ & $\mathrm{ZnO}$ \\
\hline $\mathrm{wt} \%$ & 66.87 & 0.07 & 3.00 & 0.02 & 5.00 & 1.98 & 11.97 & 8.59 & 2.50 \\
\hline
\end{tabular}

process, the temperature is higher at the bulk of the glaze than at the surface. Different temperatures provoke differences of viscous forces and buoyancy which drive this convection mechanism. The cellular structure is a revelation of the convective currents that froze during cooling [21]. The Tenorite nanocrystals float over this microstructure, decorating it. It has been possible to control the kinetic formation of the hierarchical structure by the thickness of the glass coating.

The described structure for $\mathrm{S} 150$ resembles the one observed on the surface of some hydrophobic leaves at the same scale, both in the micrometric and the nanometric scales, giving rise to the high contact angle observed in Fig. 3. The samples with matt metallic aspect (S200) show a smaller contact angle with water due to the increase of the nanostructures size and therefore a reduction of the fraction of intergranular voids on the surface that will appear under a water drop. As previously demonstrated, a higher fraction of empty spaces below the water drop produces an increase of the contact angle between them, making the surface more hydrophobic [8].

Regarding the bactericide properties, it was reported the necessity of roughness at the surface of the samples to achieve the bactericide effect [31]. The bactericide characteristics of the coatings were measured according to the standard JIS $Z$ 2801, where the number of Staphylococcus aureus bacteria before and after an ideal life bacteria environment treatment [32] is taken into account.

On control surfaces the number of bacteria increases to $7.12 \times 10^{6}$ whereas on test surface the number decreases to $10^{1}$. The results show that the population of bacteria in sample S150 decreases in 6 orders of magnitude, it is $R=5.85$, which means that sample $\mathrm{S} 150$ possesses bactericide properties. In the case of these glazes, the bactericide properties can be due to the roughness [33] or the presence of $\mathrm{CuO}$ [34] nanoparticles at the surface. In this study we obtain hierarchical structures formed by $\mathrm{CuO}$ that give raise to surface roughness. For these reasons, the bactericide effect of the glasses presented here may be due to the combination of both effects the roughness and the presence of $\mathrm{CuO}$.

It should be mentioned that the obtained hydrophobic glaze is compliant with the tile requirements about wear and chemical resistance. Moreover, the possibility to produce the glaze coatings by a well implanted industrial process, made these glazes perfectly suited for mass production. In comparison with previous works, it is possible to obtain hierarchical structures on glasses controlling the thickness of the sample and using materials available on the market. So the fabrication process is easier and the obtained hydrophobic properties are better. The combination of hydrophobic and bactericide properties is the beginning to obtain coatings with self-cleaning surfaces that would require less amount of chemical products in the daily maintenance. Thus, these coatings became sustainable from the environmental point of view.

\section{Conclusions}

Hydrophobic ceramic glazes are prepared by a conventional industrial method of the ceramic manufactory using inorganic raw materials, iron and copper. Different aesthetical effects are obtained depending on the thickness of the glaze coating. The surface of the glazes presents a microstructure similar to cells in which a nanostructure due to the crystallization of Tenorite is found. This structure is similar to the one found on the surface of different 
hydrophobic leaves. Glazes with metallic aspect show contact angles as high as $115^{\circ}$ due to the observed micro and nanostructuration on their surface. The roughness originated by the structure of the coating surface and the $\mathrm{CuO}$ presence confers to the sample bactericide properties.

\section{Acknowledgments}

The authors of this study thank the companies KERABEN and KERAFRIT for their collaboration and for supplying the necessary raw materials. They are also grateful to Nanobiomatters (NBM) Company for the bactericide test and to the Project MAT2010-21088-C03-01 for the financial support.

\section{References}

[1] T. Liu, S. Chen, S. Cheng, J. Tian, X. Chang, Y. Yin, Corrosion behavior of super-hydrophobic surface on copper in seawater, Electrochimica Acta 52 (2007) 8003-8007.

[2] C. Xue, S. Jia, J. Zhang, L. Tian, H. Chen, M. Wang, Preparation of superhydrophobic surfaces on cotton textiles, Science of Advanced Materials 9 (2008) 35008.

[3] T. Liu, Y. Yin, S. Chen, X. Chang, S. Cheng, Super-hydrophobic surfaces improve corrosion resistance of copper in seawater, Electrochimica Acta 52 (2007) 3709-3713.

[4] Z. Guao, F. Zhuo, J. Hao, W. Liu, Stable biomimetic superhydrophobic engineering materials, Journal of the American Chemical Society 127 (2005) 15670-15671.

[5] J. Kijlstra, K. Reihs, A. Klamt, Roughness and topology of ultrahydrophobic surfaces, Colloids and Surfaces A 206 (2002) 521-529.

[6] B. Bhushan, Y.C. Jung, K. Koch, Micro-, nano- and hierarchicalstructures for superhydrophobicity, self-cleaning and low adhesion, Philosophical Transactions of the Royal Society A 367 (2009) 1631-1672.

[7] B. Bhushan, Y.C. Jung, Micro- and nano-scale characterization of hydrophobic and hydrophilic leaf surfaces, Nanotechnology 17 (2006) 2758-2772.

[8] A. Cassie, S. Baxter, Wettability of porous surfaces, Transactions of the Faraday Society 40 (1944) 546-551.

[9] K. Koch, B. Bhushan, W. Barthlott, Multifunctional surface structures of plants: an inspiration for biomimetics, Progress in Materials Science 54 (2009) 137-178.

[10] K. Teshima, H. Sugimura, Y. Inoue, O. Takai, A. Takano, Transparent ultra water repellent poly (ethylene terephthalate) substrates fabricated by oxygen plasma treatment and subsequent hydrophobic coating, Applied Surface Science 244 (2005) 619-622.

[11] X.Y. Song, J. Zhai, Y.L. Wang, L. Jiang, Fabrication of superhydrophobicsurfaces by self-assembly and their water-adhesion properties, Journal of Physical Chemistry B 109 (2005) 4048-4052.

[12] B.T. Qian, Z.Q. Shen, Fabrication of superhydrophobic surfaces by dislocation-selective chemical etching on aluminum, copper, and zinc substrates, Langmuir 21 (2005) 9007-9009.

[13] M. Nosonovsky, B. Bhushan, Roughness optimization for biomimetic superhydrophobic surfaces, Microsystem Technologies 11 (2005) 535-549.

[14] S. Kamps, W. Ensinger, F. Eder, A. Berndt, H. Zeininger, Processes and structures for generation of hydrophobic surfaces for large-scale and industrial operations, Applied Surface Science 256 (2009) 92-95.

[15] T. Cedervall, I. Lynch, S. Lindman, T. Berggard, E. Thulin, H. Nilsson, K.A. Dawson, S. Linse, Understanding the nanoparticle-protein corona using methods to quantify exchange rates and affinities of proteins for nanoparticles, Proceedings of the National Academy of Sciences of the United States of America 104 (2007) 2050-2055.

[16] M. Liong, B. France, K.A. Bradley, J.I. Zink, Antimicrobial activity of silver nanocrystals encapsulated in mesoporous silica nanoparticles, Advanced Materials 21 (2009) 1684.

[17] R.M. Donlan, Biofilms: microbial life on surfaces, Emerging Infectious Diseases 8 (2002) 881-890.

[18] J.H. Hsieh, C.C. Chang, Y.K. Chang, J.S. Cherng, Photocatalitic and antibacterial properties of $\mathrm{TaON}-\mathrm{Ag}$ nanocomposite thin films, Thin Solid Films 518 (2010) 7263-7266.

[19] P. Jaquotot, A. Campillo, J.J. Reinosa, J.J. Romero, M.A. Bengochea, A. Esteban-Cubillo, et al., Development of nanostructured mutifunctional glazes, Boletin de la Sociedad Espanola de Ceramica Y Vidrio 48 (2009) 95-98.

[20] A. Moreno, Ceramic tiles: above and beyond traditional applications, Boletin de la Sociedad Espanola de Ceramica Y Vidrio 45 (2006) 59-64.

[21] J.J. Reinosa, J.J. Romero, P. Jaquotot, M.A. Bengochea, J.F. Fernández, Copper based hydrophobic ceramic nanocoating, Journal of the European Ceramic Society 32 (2012) 277-282.

[22] J.J. Reinosa, F. Rubio-Marcos, E. Solera, M.A. Bengochea, J.F. Fernández, Sintering behaviour of nanostructured glassceramic glazes, Ceramics International 36 (2010) 1845-1850.

[23] G. Longworth, N.H. Tennent, M.J. Tricker, P.P. Vaishnava, Iron-57 Mösbauer spectral studies of medieval stained glass, Journal of Archaeological Science 9 (1982) 261-273.

[24] J. Roqué, J. Molera, P. Sciau, E. Pantos, M. Vendrell-Saz, Copper and silver nanocrystals in lustre lead glazes: development and optical properties, Journal of the European Ceramic Society 26 (2006) 3813-3824.

[25] S.P. Singh, A. Kumar, Molar extinction coefficient of the cupric ion in silicate glasses, Journal of Materials Science 30 (1995) 2999-3004.

[26] J.L. Barton, M. De Billy, Diffusion and oxidation of $\mathrm{Cu}^{+}$in glass, Journal of Non-Crystalline Solids 38 (1980) 523-526.

[27] L. Bocquet, E. Lauga, A smooth future?, Nature Materials 10 (2011) 334-337

[28] Z. Burton, B. Bhushan, Surface characterization and adhesion and friction properties of hydrophobic leaf surfaces, Ultramicroscopy 106 (2006) 709-719.

[29] C. Neinhuis, W. Barthlott, Characterization and distribution of water-repellent, self-cleaning plant surfaces, Annals of Botany 79 (1997) 667-677.

[30] M. Huerta, D. Krmpotic, G.B. Mindlin, H. Mancini, D. Maza, C. Pérez-García, Pattern dynamics in a Bénard-Marangoni convection experiment, Physica D 96 (1996) 200-208.

[31] F.R. Marciano, L.F. Bonetti, J.F. Mangolin, N.S. Da-Silva, E.J. Corat, V.J. Trava-Airoldi, Investigation into the antibacterial property and bacterial adhesion of diamond-like carbon films, Vacuum 85 (2011) 662-666.

[32] J. Mungkalasiri, L. Bedel, F. Emieux, J. Doré, F.N.R. Renaud, C. Sarantopoulos, F. Maury, CVD elaboration of nanostructured $\mathrm{TiO}_{2}-\mathrm{Ag}$ thin films with efficient antibacterial properties, Chemical Vapor Deposition 16 (2010) 35-41.

[33] N. Mitik-Dineva, J. Wang, V.K. Truong, P. Stoddart, F. Malherbe, R.J. Crawford, E.P. Ivanova, Escherichica coli, Psedomonas aeruginosa, and Staphylococcus aureus attachment patterns on glass surfaces with nanoscale roughness, Current Microbiology 58 (2009) 268-273.

[34] S. Jaiswal, P. McHale, B. Duffy, Preparation and rapid analysis of antibacterial silver, copper and zinc doped sol-gel surfaces, Colloids and Surfaces B: Biointerfaces 94 (2012) 170-176. 